NBER WORKING PAPER SERIES

CAPITAL REALLOCATION AND THE CYCLICALITY OF AGGREGATE PRODUCTIVITY

\author{
Russell W. Cooper \\ Immo Schott \\ Working Paper 19715 \\ http://www.nber.org/papers/w19715 \\ NATIONAL BUREAU OF ECONOMIC RESEARCH \\ 1050 Massachusetts Avenue \\ Cambridge, MA 02138 \\ December 2013, Revised April 2021
}

We are grateful to Nick Bloom, Jesus Bueren, Thorsten Drautzburg, Michael Elsby, John Haltiwanger, Matthias Kehrig, Andrea Lanteri, Ryan Michaels, Lukas Nord, Sophie Osotimehin, Felipe Saffie and Thomas Winberry, as well as to seminar participants at the European University Institute, European Central Bank, University of Maryland, Scuola Superiore Sant'Anna in Pisa, and the SED meetings for comments and suggestions. Thanks to Dean Corbae for lengthy discussions on a related project. Cooper thanks the NSF under grant \#0819682 for financial support. This version adds an endogenous adjustment decision to our December 2013 NBER Working Paper. The views expressed herein are those of the authors and do not necessarily reflect the views of the National Bureau of Economic Research.

NBER working papers are circulated for discussion and comment purposes. They have not been peer-reviewed or been subject to the review by the NBER Board of Directors that accompanies official NBER publications.

(C) 2013 by Russell W. Cooper and Immo Schott. All rights reserved. Short sections of text, not to exceed two paragraphs, may be quoted without explicit permission provided that full credit, including $(\odot$ notice, is given to the source. 
Capital Reallocation and the Cyclicality of Aggregate Productivity

Russell W. Cooper and Immo Schott

NBER Working Paper No. 19715

December 2013, Revised April 2021

JEL No. D24,E2,E22,E32

\begin{abstract}
$\underline{\text { ABSTRACT }}$
A large part of the existing stock of capital is frequently reallocated between firms. This capital reallocation is procyclical and leads to variations in measured aggregate productivity. In this paper we ask how much of the cyclical variation in measured productivity is the consequence of capital reallocation. We study a heterogeneous-firm model that generates both realistic amounts of capital reallocation, as well as the observed relationship between the intensive and extensive margins of reallocation. We investigate the effects of exogenous shocks to total factor productivity (TFP) and to the costs of reallocation. These shocks induce changes in the amount of capital reallocation and thus cause an endogenous cyclicality of measured aggregate productivity. We find that only a model driven by exogenous TFP shocks is able to generate both dataconsistent cyclical movements in reallocation and sizeable variations in measured aggregate productivity.
\end{abstract}

\author{
Russell W. Cooper \\ Department of Economics \\ European University Institute \\ Villa La Fonte \\ Via delle Fontanelle 18 \\ I-50014 San Domenico di Fiesole (FI) \\ ITALY \\ russellcoop@gmail.com \\ Immo Schott \\ Université de Montréal \\ immo.schott@umontreal.ca \\ Canada \\ immo.schott@umontreal.ca
}




\title{
Capital Reallocation and the Cyclicality of Aggregate Productivity*
}

\author{
Russell W. Cooper ${ }^{\dagger}$ and Immo Schott ${ }^{\ddagger}$
}

April 7, 2021

\begin{abstract}
A large part of the existing stock of capital is frequently reallocated between firms. This capital reallocation is procyclical and leads to variations in measured aggregate productivity. In this paper we ask how much of the cyclical variation in measured productivity is the consequence of capital reallocation. We study a heterogeneous-firm model that generates both realistic amounts of capital reallocation, as well as the observed relationship between the intensive and extensive margins of reallocation. We investigate the effects of exogenous shocks to total factor productivity (TFP) and to the costs of reallocation. These shocks induce changes in the amount of capital reallocation and thus cause an endogenous cyclicality of measured aggregate productivity. We find that only a model driven by exogenous TFP shocks is able to generate both data-consistent cyclical movements in reallocation and sizeable variations in measured aggregate productivity.
\end{abstract}

\section{Introduction}

In a given year, about $6 \%$ of the existing capital stock of U.S. public companies is reallocated between firms through sales of existing capital and acquisitions. This capital reallocation is sizeable, adding up to almost a quarter of total investment. In an average year between 1972 and 2018, 43\% of firms sell part of their existing capital, while $29 \%$ make an acquisition (12\% do both).

The existing literature establishes a number of key facts about capital misallocation which are informative about the gains from reallocation. First, from Restuccia and Rogerson (2008), Hsieh and Klenow (2009) and others, misallocation can explain long-run differences in economic performance. Second, there are productivity gains from reallocation, as established in Olley and Pakes (1996), Maksimovic and Phillips (2001), and Foster, Haltiwanger, and Syverson (2008) among others. Finally, Eisfeldt and Rampini (2006) documented that the capital reallocation process is procyclical, i.e. more capital is reallocated during times when aggregate output is high.

The correlation highlighted by Eisfeldt and Rampini (2006) is suggestive: capital reallocation may contribute to fluctuations in measured aggregate productivity. If so, then observed cyclical variations in the

${ }^{*}$ We are grateful to Nick Bloom, Jesus Bueren, Thorsten Drautzburg, Michael Elsby, John Haltiwanger, Matthias Kehrig, Andrea Lanteri, Ryan Michaels, Lukas Nord, Sophie Osotimehin, Felipe Saffie and Thomas Winberry, as well as to seminar participants at the European University Institute, European Central Bank, University of Maryland, Scuola Superiore Sant'Anna in Pisa, and the SED meetings for comments and suggestions. Thanks to Dean Corbae for lengthy discussions on a related project. Cooper thanks the NSF under grant \#0819682 for financial support. This version adds an endogenous adjustment decision to our December 2013 NBER Working Paper.

${ }^{\dagger}$ Department of Economics, European University Institute and NBER, russellcoop@gmail.com

${ }^{\ddagger}$ Department of Economics, Université de Montréal and CIREQ, immoschott@gmail.com 
Solow residual might be explained as an outcome of the reallocation process. More capital reallocation leads to a better allocation of resources across firms, which implies higher measured aggregate productivity. This paper explores this conjecture. We ask: How much of the observed cyclical variation in aggregate productivity can be explained by capital reallocation?

The framework for analysis is a heterogeneous firm model in which the movement of capital across producers entails adjustment frictions. This implies productivity gains from reallocation because marginal products are not equalized. Changes in aggregate conditions lead to endogenous variations in capital reallocation. This causes fluctuations in the Solow residual, or measured aggregate productivity.

As indicated by the distribution of reallocation rates in Figure 1, a key feature of firm-level data is a large amount of heterogeneity in reallocation rates. The model captures this heterogeneity and quantifies its importance for cyclical changes in aggregate productivity.

Figure 1: Histogram of firm-level reallocation rates

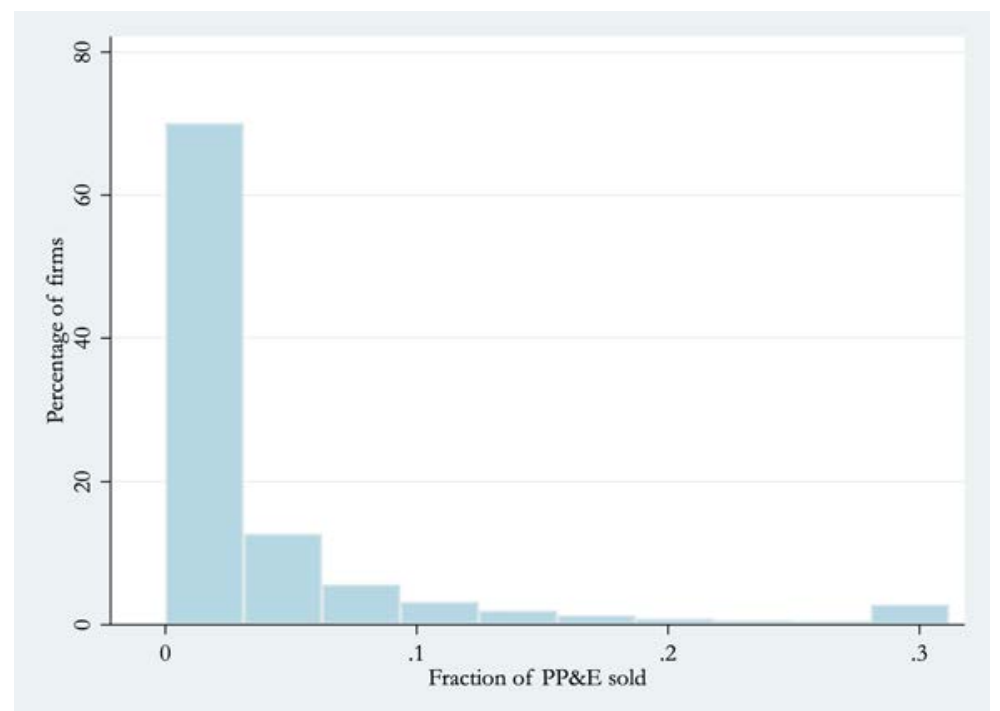

Notes: Histogram of non-zero firm-level sales of property, plant, and equipment (PPE) as a fraction of net property, plant, and equipment. Observations more than two standard deviations above the mean were winsorized. Source: Compustat 1971-2018.

We solve the model as a planner's problem in an economic environment that isolates the role of frictions to the capital reallocation process 11 Our setup allows for an analytical characterization of the solution, which entails higher order moments of the joint cross sectional distribution of productivity and capital. This distribution is a slow-moving object and thus has the potential to create endogenous propagation.

The model is calibrated to match both the key microeconomic and macroeconomic facts about the capital reallocation process. Specifically, the steady state of the model exactly matches the empirical targets on the fraction of reallocating firms, the average amount of capital reallocation, and the dispersion in revenue-based total factor productivity.

We then use this model as a foundation for the study of cyclical reallocation and productivity. Two principal sources of fluctuations are introduced: (i) shocks to aggregate TFP and (ii) shocks to the distribution

\footnotetext{
${ }^{1}$ An earlier version of this paper, Cooper and Schott (2020), includes a section with capital accumulation but that possibility added little to the interaction between reallocation and productivity.
} 
of adjustment costs. The parameters for these stochastic processes are estimated using empirical moments on the cyclicality of capital reallocation, as well as the time-series variation in the cross-sectional dispersion of reallocation rates. This choice of moments ensures that the key macroeconomic characteristic of aggregate reallocation is generated by the model economy, while at the same time reproducing realistic cyclicality in the amount of capital reallocation.

We have two main findings: First, the model economy driven by exogenous variations in aggregate productivity can induce movements in capital reallocation that match the micro- and macro data on reallocation and generate realistic business cycles. Second, the model economy driven by variations in the costs of reallocation generates an endogenous movement of capital across heterogenous firms that matches the cyclicality of reallocation and creates an endogenous, procyclical Solow residual. However, this model can only generate about $7 \%$ of the observed variation in aggregate productivity. From this perspective, we conclude that the correlation between productivity and reallocation stems from the effects of exogenous productivity shocks on reallocation. This is not to say that reallocation is not important for longer-run economic phenomena. But at the business cycle frequency, reallocation of capital is not a driving force.

Related Literature A large body of work has studied the process of capital reallocation empirically (e.g. Olley and Pakes (1996), Maksimovic and Phillips (2001), Ramey and Shapiro (2001)). A main conclusion is that the reallocation process is productivity-enhancing (Foster et al., 2008, Osotimehin, 2019). Such findings have motivated the question to what extent frictions to the reallocation process can explain the observed productivity differences both across and within countries. The common idea of this literature is that frictions in the reallocation process lead to the misallocation of factors of production (relative to a frictionless benchmark) and affect aggregate productivity. Removing these frictions, which can either take the form of unspecified 'wedges' (Restuccia and Rogerson, 2008; Hsieh and Klenow, 2009) or specific policies (Guner, Ventura, and $\mathrm{Xu}, 2008$, Kaymak and Schott, 2019) is found to entail large productivity gains, especially when the frictions are positively correlated with firm-level productivity (Bartelsman, Haltiwanger, and Scarpetta, 2013). Importantly, these papers study long-run productivity gains. In this paper we investigate the conjecture that at least some of the fluctuations in aggregate productivity at the business cycle frequency could be the consequence of the dynamics of capital reallocation.

Our analysis builds upon Eisfeldt and Rampini (2006), who established two important empirical regularities: Among publicly listed U.S. firms, capital reallocation is strongly procyclical, while measures of productivity dispersion, interpreted as 'benefits' to reallocation, are countercyclical, or acyclical 2 The results in Eisfeldt and Rampini (2006) suggest an important role for cyclical movements in the costs of reallocation. Differently from Eisfeldt and Rampini (2006), our economic environment includes a joint distribution of capital and idiosyncratic productivity. This allows us to perform a quantitative analysis using a model economy that replicates both macroeconomic regularities and the underlying microeconomic heterogeneity. Further, our analysis highlights the role of non-convex adjustment costs, allowing us to match moments on both the extensive and intensive margins of firm-level changes in capital.

Lanteri (2018) studies capital reallocation in a model with an explicit market for secondary capital to generate endogenous partial irreversibility. He presents evidence for a procyclical secondary market price of capital and generates procyclical capital reallocation in a model with aggregate productivity shocks. Lanteri (2018) focuses on the business cycle properties of a DSGE model with an endogenous resale price of capital. We focus solely on capital reallocation with an emphasis on cross sectional properties of the economy. Our

\footnotetext{
${ }^{2}$ Countercyclical productivity dispersion is central to many studies and this empirical regularity has often been replicated, e.g. in Bloom (2009), Kehrig (2015), and Bachmann and Bayer 2014).
} 
aim is to construct a model that matches both the cyclical character of aggregate capital reallocation, as well as the heterogeneity in micro-level reallocation behavior. This ensures that both the overall amount of capital reallocation, and the dispersion in reallocation rates are data-consistent. This is important given our focus on understanding sources of exogenous variation that explain sizeable variations in aggregate productivity and match the reallocation moments.

One finding in Lanteri (2018) is that an economy subject only to aggregate productivity shock generates little endogenous feedback from capital reallocation. Our results confirm this result. We go further by investigating other sources of exogenous variation, particularly variations in the cost of reallocation as stressed in Eisfeldt and Rampini (2006) and show that these alternative causes of business cycles either fail to match the reallocation moments or fail to generate sizable movements in measured aggregate productivity.

Finally, in comparison to most quantitative dynamic general equilibrium models, we do not rely on a computationally heavy quantitative solution in the tradition of Krusell and Smith (1998). Our setup allows for an analytical characterization of the solution, which entails higher order moments of the cross sectional distribution of productivity and capital. We are able to analyze to what extent quantitatively plausible variations in aggregate conditions are able to generate capital reallocation and affect measured aggregate productivity.

\section{Reallocation and productivity}

To fix basic ideas, consider an economy without aggregate shocks $3^{3}$ The economy is composed of a representative household and a mass of firms distinguished by productivity and adjustment costs. We first discuss the basic environment. An important derivation links the Solow residual to the cross sectional distribution of capital. Then the stationary equilibrium is computed and matched to a subset of moments.

\subsection{Environment}

The production function at any plant is

$$
y(k, \varepsilon)=A \varepsilon k^{\alpha},
$$

where $A$ is (fixed) aggregate TFP, and $k$ is the capital used at the plant with idiosyncratic productivity $\varepsilon !^{4}$ Throughout, the aggregate capital stock is fixed at $K$, allowing us to focus on reallocation alone.

Idiosyncratic productivity shocks are persistent. Every period, with probability $1-\rho_{\varepsilon}$ a production site draws a new level of $\varepsilon$ from a log-normal distribution. This new draw is unconditional on $\varepsilon_{t-1}$. With the counter-probability $\rho_{\varepsilon}$ the productivity level remains unchanged:

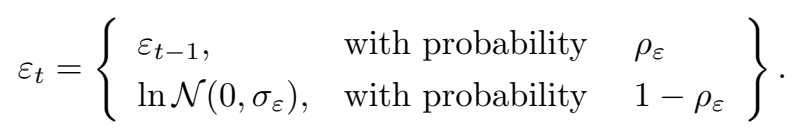

The invariant distribution of $\varepsilon$ is denoted $f(\varepsilon)$.

We assume $\alpha<1$ as in Lucas (1978). The assumption of diminishing returns to scale implies that the allocation of capital across production plants is non-trivial. There are gains to allocating capital to high productivity sites but as $\alpha<1$, capital is also spread across plants.

\footnotetext{
${ }^{3}$ Aggregate shocks are added in Section 4 for the study of cyclical reallocation.

${ }^{4}$ The model does not distinguish between plants and firms and the terms are used interchangeably throughout. Labor and other inputs are not made explicit. One interpretation is that these inputs have no adjustment costs and are optimally chosen each period, given the state.
} 
Following the realizations of plant-specific $\varepsilon$, capital can be reallocated across production sites. Capital reallocation is costly. Our approach is to specify and estimate a minimalist adjustment cost structure. Specifically, in order to learn about the plant-specific state $(k, \varepsilon)$ before reallocation and production take place, a fixed adjustment cost $F$ must be paid. The adjustment $\operatorname{cost} F$ is independently and identically distributed across time and plants with a CDF given by $G(F)$. As in Eisfeldt and Rampini (2006), these costs can be interpreted as information frictions rather than physical adjustment frictions $5^{5}$

This specification of the adjustment cost has three important features. First, combining costs of adjustment and information acquisition makes the analysis considerably more tractable. In fact, many of our results are analytic. Second, the specification cleanly separates the costs and benefits of reallocation. As there is no state dependence in the adjustment choice, the likelihood of adjustment is independent of the individual plant profitability. This does not bias our analysis against finding a large role for capital reallocation, as, we explain below, when discussing the generality of our findings. Third, many models of costly capital adjustment have difficulty matching small investment rates ${ }^{6}$ This is not a problem in our formulation: after paying the information acquisition cost, capital adjustment might be minimal if the current level of capital is sufficiently close to the optimal level of capital given $\varepsilon$.

\subsection{Optimal allocations}

In the presence of reallocation costs, the choice problem of a social planner is

$$
V(\Gamma(k, \varepsilon))=\max _{\pi, \tilde{k}_{a}(k, \varepsilon)} u(c)+\beta E_{\Gamma^{\prime} \mid \Gamma} V\left(\Gamma^{\prime}(k, \varepsilon)\right)
$$

subject to

$$
\begin{aligned}
y & =\int_{(k, \varepsilon) \in a} A K^{\alpha} \varepsilon \tilde{k}_{a}(k, \varepsilon)^{\alpha} d \Gamma(k, \varepsilon)+\int_{(k, \varepsilon) \in n} A K^{\alpha} \varepsilon \tilde{k}_{n}(k, \varepsilon)^{\alpha} d \Gamma(k, \varepsilon), \\
K & =\int_{(k, \varepsilon) \in a} \tilde{k}_{a}(k, \varepsilon) d \Gamma(k, \varepsilon)+\int_{(k, \varepsilon) \in n} \tilde{k}_{n}(k, \varepsilon) d \Gamma(k, \varepsilon), \\
c & =y-\int_{0}^{F(\pi)} F K d G(F) .
\end{aligned}
$$

In this optimization problem the state variable of the planner is the joint distribution over plant level productivity and capital prior to reallocation, denoted by $\Gamma(k, \varepsilon)$, explained below.

There are two controls in (3). The planner determines $\pi$, the fraction of plants that will be adjusted, and chooses how to allocate capital among adjusting plants. The adjustment status of a plant is given by $j \in\{a, n\}$, where $a$ stands for 'adjusting', while $n$ stands for 'not adjusting'. This status is determined by whether or not a plant's fixed cost of adjusting is paid. Let $\tilde{k}_{j}(k, \varepsilon)$ for $j \in\{a, n\}$ denote the fraction of aggregate capital allocated to a plant with adjustment status $j$ that enters the period with capital $k$ and productivity $\varepsilon$. The capital of plants in the set of adjusters is optimally set by the planner to a level $\tilde{k}_{a}(k, \varepsilon)$. The capital of plants in the group of non-adjusters remains unchanged, i.e. $\tilde{k}_{n}(k, \varepsilon)=k$.

Here output is simply the sum of the production from adjusting and non-adjusting plants, as in (4), while aggregate capital is the sum of capital in the two types of plants, as in (5). In the resource constraint (6)

\footnotetext{
${ }^{5}$ Section 4 of Eisfeldt and Rampini (2006) provides a lengthy discussion and interpretation of these adjustment costs.

${ }^{6}$ For example, Cooper and Haltiwanger (2006) match the extremes of the investment rate distribution but generate no small adjustments.
} 
the adjustment cost are linked to the fraction of adjusting plants $\pi$ through the CDF of adjustment costs 7 Specifically, given $\pi$, the planner selects plants starting with the lowest adjustment costs until the desired fraction $\pi$ of plants are adjusted. Through this process, the maximal cost incurred is denoted $F(\pi)$ and given implicitly by $\pi=G(F)$. Once the maximal adjustment cost is determined, the total amount paid is the integral over the distribution of adjustment costs up to $F(\pi)$, as in the last term of (6).

As a benchmark, consider the planner's problem in the absence of adjustment costs. The objective is to maximize output (consumption) through an optimal allocation of capital. The cross-sectional distribution is no longer a state variable. The resulting first-order condition is

$$
\tilde{k}_{a}(k, \varepsilon)=K \frac{\varepsilon^{\frac{1}{1-\alpha}}}{\int_{\varepsilon} \varepsilon^{\frac{1}{1-\alpha}} f(\varepsilon) d \varepsilon}
$$

for all $k, \varepsilon 8$ The optimal capital allocation equalizes marginal products of capital across plants. For adjusters, this allocation depends on $\varepsilon$ but, as is clear from the right side of (7), is independent of $k$.

Adjustment costs imply that the reallocation problem is dynamic. They create two distinct dimensions linked to the capital reallocation problem, an intensive and an extensive margin. The extensive margin relates to the fraction of adjusting plants $\pi$, while the intensive margin is controlled by the planner through the assignment function $\tilde{k}_{a}(k, \varepsilon)$. Both instruments influence the distribution of capital across plants but imply different costs. Choosing a higher $\pi$ enlarges the set of adjusting plants. This has the benefit of increasing output today but increases the total adjustment costs. Choosing an allocation of capital $\tilde{k}_{a}(k, \varepsilon)$ that reduces the dispersion in marginal products of capital also increases output today. Here, costs arise due to future adjustment costs. Given that a fraction $1-\rho_{\varepsilon}$ of plants will receive a new productivity draw next period, a fraction of plants will be not be at their optimal $k$ in the future. This entails larger future extensive margin adjustments and higher future adjustment costs. For this reason, $\tilde{k}_{a}(k, \varepsilon)$ will differ from the frictionless capital allocation satisfying (7).

We define reallocation of capital as the fraction of total capital that is moved between adjusting plants within a period. As $\tilde{k}_{a}(k, \varepsilon)$ denotes the post-reallocation capital stock of adjusting plants with initial capital $k$ and productivity $\varepsilon$, plant-level reallocation level would be $r(k, \varepsilon)=\left|\tilde{k}_{a}(k, \varepsilon)-k\right|$. Aggregating over all adjusting plants, the aggregate reallocation level is

$$
R \equiv 0.5 \int_{(k, \varepsilon) \in a} r(k, \varepsilon) d \Gamma(k, \varepsilon)
$$

The multiplication by 0.5 avoids double counting flows between adjusting plants.

\section{$2.3 \quad$ Aggregate productivity}

For this economy, there exists a fundamental link between productivity and the assignment of capital to plants 9 This link lies at the heart of our analysis of reallocation and aggregate productivity. Aggregate output in 4 can be rewritten as

$$
y=A K^{\alpha}\left[\pi\left(\mu_{a}+\phi_{a}\right)+(1-\pi)\left(\mu_{n}+\phi_{n}\right)\right]=\tilde{A} K^{\alpha},
$$

\footnotetext{
${ }^{7}$ As in Cooper and Haltiwanger (2006), the adjustment cost is proportional to $K$.

${ }^{8}$ Derivations can be found in Appendix B

${ }^{9}$ This builds on Olley and Pakes (1996).
} 
where, for $j=\{a, n\}$, define $\mu_{j} \equiv \mathbb{E}\left(\varepsilon \tilde{k}_{j}(k, \varepsilon)^{\alpha}\right)$ as the product of average productivity and average effective capital, while $\phi_{j} \equiv \operatorname{Cov}\left(\varepsilon, \tilde{k}_{j}(k, \varepsilon)^{\alpha}\right)$ is the covariance between the two terms.

The values $\mu_{n}$ and $\phi_{n}$ pin down output among non-adjusting plants and are determined by the current state, the joint distribution of productivity and capital $\Gamma$. Output among adjusting plants is controlled through the assignment function $\tilde{k}_{a}(k, \varepsilon)$. This assignment of capital to adjusting plants implies values for the mean and covariance terms $\mu_{a}$ and $\phi_{a}$. Finally, the choice of a fraction of adjusting plants $\pi$ determines the relative mass of adjusters and non-adjusters.

Researchers interested in measuring TFP from the aggregate data will typically uncover $\tilde{A}$, the Solow residual, rather than $A$. From (9) there are two factors which influence $\tilde{A}$. The first one is $A$. The influence of $A$, aggregate TFP, is direct and has been central to many studies of aggregate fluctuations. The second effect on $\tilde{A}$ comes from endogenous changes in the allocation of capital to production sites. Both changes in the fraction of adjusting firms $\pi$ (the extensive margin), as well as changes in the target allocation of capital $\tilde{k}_{a}$ (the intensive margin) impact the Solow residual. The aggregate shocks we consider below will lead to endogenous changes in capital reallocation, thereby impacting the Solow residual through reallocation.

\subsection{Joint distribution of capital and productivity}

In the presence of reallocation frictions, the state of the economy includes the joint distribution of plant specific capital, $k$, and the idiosyncratic shock, $\varepsilon$, denoted as $\Gamma(k, \varepsilon)$. This distribution determines the level of output that is produced at non-adjusting plants. Consequently, when making reallocation decisions the planner needs to forecast $\Gamma^{\prime}$. The evolution of this distribution reflects the persistence in the idiosyncratic shocks as well as the choices about the fraction of adjusting plants $\pi$ and the assignment of capital among adjusting plants $\tilde{k}_{a}(k, \varepsilon)$.

An advantage of our setup is that although the model is rich due to plant heterogeneity and nonconvex adjustment costs, it allows for an exact analytical representation of the joint distribution and its evolution. Different from the literature following Krusell and Smith (1998) we are not bound by computational limitations to a numerical approximation of this joint distribution. Instead of keeping track of the infinite-dimensional joint distribution $\Gamma$, we retain $\mu_{n}$ and $\phi_{n}$ in the state vector of (3). Together with the choices $\pi$ and $\tilde{k}_{a}(k, \varepsilon)$ this pins down contemporaneous output in (9). Importantly, the higher-order moment, $\phi_{n}$ is part of the state of economy. This moment represents the dependence of output on the assignment of capital to firms. Dynamics in the cross-sectional joint distribution of capital and productivity will induce time series variation in the Solow residual even in the absence of serially correlated aggregate shocks. The moments $\mu_{n}$ and $\phi_{n}$ are essential for capturing these dynamics in the analysis that follows.

The law of motion for the distribution $\Gamma$ can be written as a convex combination of the moments from the adjusting and non-adjusting plants, weighted respectively by $\pi$ and $1-\pi 10$

$$
\begin{aligned}
& \mu_{n}^{\prime}=(1-\pi) \mu_{n}+\pi \mu_{a} \\
& \phi_{n}^{\prime}=\rho_{\varepsilon} \cdot\left((1-\pi) \phi_{n}+\pi \phi_{a}\right) .
\end{aligned}
$$

Note that in the absence of aggregate shocks, this economy has a stationary joint distribution of capital

\footnotetext{
${ }^{10}$ See Appendix $\mathrm{B}$ for derivations.
} 
and productivity, given by

$$
\begin{aligned}
\mu_{n} & =\mu_{a} \\
\phi_{n} & =\phi_{a} \cdot \frac{\pi}{\pi+\frac{1-\rho_{\varepsilon}}{\rho_{\varepsilon}}} .
\end{aligned}
$$

This implies that steady-state consumption is given by

$$
c=A K^{\alpha}\left(\mu_{n}+\frac{\phi_{n}}{\rho_{\varepsilon}}\right)-K \int_{0}^{F(\pi)} F d G(F) .
$$

These characterizations reflect the tradeoffs the planner is facing. Spreading capital more evenly across plants increases $\mu_{n}$ but lowers the covariance with productivity $\phi_{n}$. Increasing the fraction of adjusting plants $\pi$ increases the steady-state covariance between sites' productivity and capital from (13), but raises the amount of adjustment costs paid.

\section{Quantitative analysis: Steady State}

In this section, we estimate a quantitative version of the model developed in section 2 The goal is to match key characteristics of the microeconomic adjustment behavior of plant-level changes in capital. For this, the steady state properties of the model are matched with those of the data to set a couple of key parameters characterizing plant-level choices 11

\subsection{Parametrization}

We begin by calibrating the steady state of the model described in Section 2.2 . The parameters are chosen by targeting moments that characterize capital reallocation and the importance of idiosyncratic shocks.

There are six parameters in the steady state of the model, summarized in the upper part of Table 1. The first two parameters describe the household's discount factor and risk aversion and are set outside the model. To determine the returns to scale parameter $\alpha$, we estimated the curvature of the revenue function using firm-level data and found a value of $0.811{ }^{12}$

The second part of Table 1 presents the results of a simulated method of moments (SMM) estimation. We estimate three parameters. The persistence and standard deviation of idiosyncratic shocks are denoted as $\rho_{\varepsilon}$ and $\sigma_{\varepsilon}$. To parameterize the adjustment costs, we assume that $G(F)$ is uniform between zero and an upper limit denoted $b$, as in Thomas (2002). The parameter vector $\Theta=\left(\rho_{\varepsilon}, \sigma_{\varepsilon}, b\right)$ is chosen to minimize the distance between data and model moments, as shown in Table 2.

While there is no one-to one mapping between parameters and moments, the data moments were chosen to be informative about the underlying parameters. The first two moments are the fraction of firms that adjust capital and the fraction of total capital that is reallocated in a given period. These moments are informative about the importance of the capital adjustment cost and about the persistence of idiosyncratic productivity shocks. If reallocation is less costly, capital in a larger fraction of plants will be reallocated, but a lower amount of reallocation is required each period. A higher persistence of idiosyncratic productivity

\footnotetext{
${ }^{11}$ All data moments were computed from Compustat. Details can be found in Appendix A

${ }^{12}$ We provide a robustness analysis with respect to this and other parameters in Appendix C
} 
Table 1: Parameters

\begin{tabular}{crrr}
\hline Parameter & Meaning & Value & Source \\
\hline$\beta$ & Discount factor & 0.962 & Annual $r=4 \%$ \\
$\gamma$ & Risk aversion & 1 & Log utility \\
$\alpha$ & Compustat \\
\hline$\rho_{\varepsilon}$ & Persistence of $\varepsilon$ & 0.924 & \\
$\sigma_{\varepsilon}$ & Std. dev. of $\varepsilon$ & 0.366 & $c f$. Table 2 \\
$b$ & Adjustment cost upper bound & 0.136 & \\
\hline \hline$\rho_{A}$ & Persistence of $A$ & 0.617 & \\
$\sigma_{A}$ & Standard deviation of $A$ & 0.037 & $c f$. Table 3 \\
$\rho_{b}$ & Persistence of $b$ & 0.977 & \\
$\sigma_{b}$ & Standard deviation of $b$ & 0.023 & \\
\hline
\end{tabular}

Note.- Model parameters. The parameters in upper part of the table were preassigned. The parameters in the second part of the table were estimated for the stationary economy using SMM. The lower part of the table shows the parameters of the various aggregate shock processes for the model with aggregate fluctuations.

implies lower reallocation rates and a lower fraction of adjusting plants ${ }^{13}$ The third moment is the valueadded weighted standard deviation of firm-level productivity. We measure revenue-based productivity in the data using a semiparametric procedure following Olley and Pakes (1996). In the model, the standard deviation in firm-level productivity is governed by $\sigma_{\varepsilon}$. Additionally, a higher $\sigma_{\varepsilon}$ implies that productivity is more dispersed among plants, leading to more reallocation.

Table 2: Moments from the Stationary Economy

\begin{tabular}{lrrr}
\hline & $\mathrm{R}>0$ & $R / K$ & $\sigma_{\text {TFPR }}$ \\
\hline Data & 0.620 & 0.057 & 0.329 \\
Model & 0.620 & 0.057 & 0.329 \\
\hline
\end{tabular}

Note.- The moments are i) the time-series average of the fraction of firms with positive capital reallocation, ii) the time-series average of the amount of capital reallocation (as a fraction of total capital), iii) the time-series average of the value-added weighted standard deviation of firm-level revenue-based productivity (TFPR).

Table 2 shows an exact fit between the data and the model. The model reproduces key features of the data on capital reallocation and productivity dispersion across firms. In particular, the model generates the large fraction of plants with positive changes in capital, while simultaneously matching the fraction of total capital that is being reallocated. The model also matches the empirical firm-level dispersion in revenue-based productivity (TFPR) 14

Despite its simplicity, the model fits a series of untargeted moments. The estimated parameters in Table 2 imply an autocorrelation of firm-level sales of 0.935 in the model, compared to 0.908 in the data. The model generates a positive correlation between productivity and capital reallocation at the micro-level $(0.27$ in the data and 0.48 in the model), and a low serial correlation of plant-level capital reallocation (-0.005 in

\footnotetext{
${ }^{13}$ Note that, as stressed in Lanteri $(2018)$, Compustat provides a measure of the dollar value of capital reallocation, so that changes in reallocation might be driven by prices rather than quantities. Our measures of reallocation are not subject to this concern because $R>0$ is an extensive margin measure and $R / K$ measures the fraction of reallocated capital.

${ }^{14}$ In the data, it is TFPR that is measured. In the model, there is no difference between TFPR and aggregate productivity TFP.
} 
the data and -0.003 in the model). The microeconomic adjustment behavior is also in line with the empirical counterpart. As was shown in Figure 1, the empirical distribution of capital adjustments is characterized by a large number of 'small' capital adjustments. In the quantitative model, the smallest $10 \%$ of positive capital adjustments make up for around $85 \%$ of all adjustments. The same number is equal to $70 \%$ in the data. The model implies total capital reallocation costs of $2.3 \%$ of aggregate output.

\subsection{Reallocation and aggregate productivity}

The analysis here makes use of the tractability of our model setup to generate some intuition for why the steady state effects of changes in the economy's allocative efficiency are potentially large, while the feedback effect of aggregate shocks that is generated through reallocation is likely to be small. Within the steady state, capital is constantly being reallocated across heterogeneous firms. Due to the frictions, reallocation generates productivity gains. Using the parameterization of the model, even in the absence of aggregate shocks, we can quantify this productivity gain from reallocation on the Solow residual, which is defined as

$$
\tilde{A}=A \cdot\left(\pi \cdot\left(\mu_{a}+\phi_{a}\right)+(1-\pi) \cdot\left(\mu_{n}+\phi_{n}\right)\right) .
$$

There are two reasons why reallocation is productivity enhancing. First, there is the extensive margin. From [15), a higher $\pi$ increases the fraction of adjusting plants and reduces the fraction of inactive ones. Second, conditional on adjustment, there is the intensive margin. After having paid the adjustment costs, the allocation of capital among adjusting plants $\tilde{k}_{a}(k, \varepsilon)$ is chosen to optimally solve the tradeoff between exploiting differences in productivity and decreasing returns. The resulting allocation is characterized by a higher covariance between productivity and capital $\phi_{a}$ than for non-adjusting plants. In our calibrated economy, $\phi_{a}$ is $13.2 \%$ higher than $\phi_{n} 15$ Among non-adjusting plants, changes in idiosyncratic productivity may have caused the capital stock to be out of sync with this optimal level. As a result, the dispersion in average products of capital is an order of magnitude larger among non-adjusting plants.

Large long-run effects The previous analysis suggests that in an economy's steady state there are potentially large gains from an improved factor allocation. Panel (a) of Figure 2 shows the marginal effect of changes in the fraction of active plants, $\pi$, on the steady state Solow residual ${ }^{16}$ Changes in $\pi$ affect the fraction of adjusting plants, and, because of persistence in productivity, affect the steady-state covariance term $\phi$, even among non-adjusting plants (see (13)). Figure 2 makes clear that for low levels of $\pi$, the marginal effect on aggregate productivity is very large because of substantial differences in marginal productivities among adjusting and non-adjusting firms. For example, our results imply a 10.3\% decrease in aggregate productivity if $\pi$ were to be exogenously reduced to $25 \%$ of the level currently observed among U.S. firms. There are possibly large losses from reductions in capital reallocation.

The steady state value of $\pi$ that resulted from the calibration of the model is indicated by the red dot in panel (a) of Figure 2. It shows that for intermediate to high levels of $\pi$, the marginal effect on aggregate productivity is significantly weaker. Our calculations imply that there are few potential long-run gains from further facilitating capital reallocation in the U.S. economy. The key to understanding this result is that there are two dimensions to capital reallocation, an average and a marginal effect. If a large number of

\footnotetext{
${ }^{15}$ In the steady state $\mu_{a}=\mu_{n}$, see equations $[12$ and $\sqrt{13}$. Our calibration implies that average output is about $5 \%$ higher among adjusting plants.

${ }^{16}$ For this exercise we consider exogenous changes in the steady state level of $\pi$, while keeping all other model parameters constant.
} 
plants selects into capital adjustment, this significantly increases capital reallocation and measured aggregate productivity. Yet at the same time, the marginal effect of further increases in reallocation on productivity is very small. The marginal effect at the red dot is small because most of the long-run gains to reallocation have already been exhausted.

Figure 2: Long-run vs. short-run effects of changes in reallocation

(a) Long-run: Effect of $\pi$ on SR

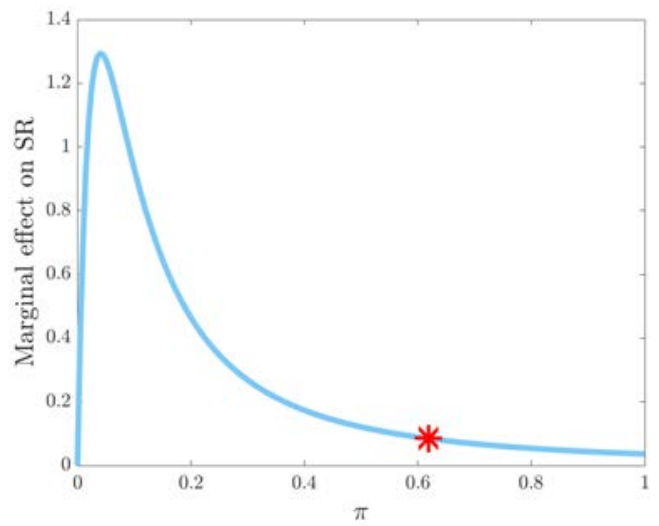

(b) Short-run: Effects of $A$ and $b$ on SR

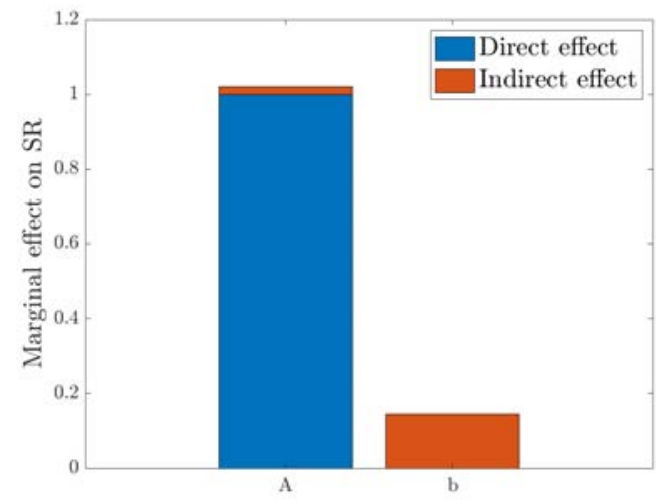

Notes: Panel (a): The steady-state level of $\pi$ is on the x-axis, the marginal effect on aggregate productivity $\tilde{A}$, given by 15 , is on the y-axis. The blue line shows the marginal change in $\tilde{A}$ resulting from a marginal change in $\pi$, taking into account the effect of $\pi$ on $\tilde{k}_{a}(k, \varepsilon)$. The red dot indicates the level of $\pi$ implied by the calibration of the steady state economy in Section 3.1 Panel (b): The bars show the derivative of $\tilde{A}$ with respect to $A$ and $b$. The effect of a marginal increase in $A$ is decomposed into a direct and an indirect effect. See Appendix $B$ for details.

Small short-run effects Our steady-state results allow us to quantify the effects of temporary changes in aggregate variables on measured aggregate productivity $\tilde{A}$. Changes in aggregate variables can cause changes in capital reallocation, which will impact aggregate productivity through endogenous changes in the joint distribution of capital and productivity. In particular, we consider two factors, aggregate TFP, denoted as $A$, and the cost of capital adjustment $b$. From (15), aggregate TFP has a direct effect on $\tilde{A}$, as discussed above. In addition, changes in $A$ affect capital reallocation through an indirect effect on the optimal choices, $\pi$ and $\tilde{k}_{a}$. Changes in $b$ do not have a direct effect on the Solow residual but lead to more reallocation due to a reduction in the reallocation cost.

Panel (b) of Figure 2 shows a decomposition of the effect on the Solow residual from marginal changes in $A$ or $b$. We quantify these effects by recomputing the optimal choices of $\pi$ and $\tilde{k}_{a}(k, \varepsilon)$ following a change in $A$ or $b$. Two results stand out. First, marginal changes in $A$ have a much larger effect on the Solow residual than changes in $b$. Second, it is apparent that the direct effect of $A$ dominates the indirect effect. In particular, the results imply that a $1 \%$ reduction in $b$ increases measured aggregate productivity by about $0.15 \%$. Although changes in the cost of reallocation produce comparatively large indirect effects on the Solow residual through reallocation, one can anticipate that empirically plausible exogenous changes in $b$ will have difficulty matching the amount of cyclical variation in measured productivity. 


\section{Quantitative Analysis: Aggregate Fluctuations}

This section sets out to answer the questions asked in the introduction. How much of the cyclical variation in measured productivity is the consequence of capital reallocation? Can endogenous movements in productivity, caused by capital reallocation create cyclical variations in measured productivity that resemble business cycles?

One possibility is that capital reallocation is a consequence of variations in aggregate productivity. That is, in response to TFP shocks the gains to reallocation are larger and hence reallocation is procyclical. A second prospect is the opposite causality: variations in the costs of reallocation lead to changes in measured productivity. In this setting, consistent with the emphasis in Eisfeldt and Rampini (2006), the costs of reallocation are the driving force. Reallocation would be the primary source of variations in aggregate productivity through the induced movements in the Solow residual.

To study these questions, we build on the analysis of the steady state and augment the model with aggregate fluctuations. To the state variables in the planner's optimization problem, as stated in (3)-(6) we add an aggregate shock - denoted as $S$, together with its law of motion, detailed below.

We consider two different sources of aggregate fluctuations: (i) TFP shocks and (ii) variations in the cost of reallocation. For both of these cases, we estimate the parameters governing the evolution of the respective aggregate shock. Each shock is assumed to follow an AR(1) process in logs, characterized by an autocorrelation $\rho_{S}$ and a standard deviation of the innovations, $\sigma_{S}$. These parameters are chosen to match moments characterizing cyclical capital reallocation. We target $i$ ) the correlation between aggregate productivity and capital reallocation, and ii) the time-series average of the standard deviation of the aggregate amount of capital reallocated (as a fraction of total capital). The resulting parameter estimates are shown in the lower part of Table 1. A comparison between the data moments and the model moments is shown in Table 3 .

The first moment in Table 3 indicates that capital reallocation is procyclical, a key fact first emphasized in Eisfeldt and Rampini (2006). Our measure of aggregate productivity is the Solow residual, defined as $\tilde{A}$ in (9). Through the lens of our model, the Solow residual is independent of $K$ and can be constructed from observations on $Y$ and $K$, using the estimate of $\alpha{ }^{17}$ The second moment in Table 3 is $\sigma(R / K)$, which is informative about the magnitude of capital reallocation. Indirectly, by matching this moment we discipline the variability of the shocks that drive capital reallocation.

Table 3: Moments: Cyclical reallocation

\begin{tabular}{lcc}
\hline & $c(R, \tilde{A})$ & $\sigma(R / K)$ \\
\hline Data & 0.547 & 0.018 \\
A Model & 0.548 & 0.018 \\
B Model & 0.548 & 0.018 \\
\hline
\end{tabular}

Note.- The moments are i) the correlation between the detrended natural logarithm of Solow residual and the detrended timeseries of the natural logarithm of total capital capital reallocation, ii) the time-series average of the standard deviation of the fraction of aggregate capital reallocated. Model results from simulation of $\mathrm{T}=20,000$ periods. Data source: Compustat. See Appendix A for details.

\footnotetext{
${ }^{17}$ Our measure of $\tilde{A}$ co-moves very closely with alternative measure of aggregate output, such as GDP. All of the data moments reported throughout the paper are robust to using GDP as a measure of the business cycle. As an alternative to $R$, the total amount of capital reallocation, we also considered measuring cyclical reallocation in the data by using $R / K$, in order to address the fact that changes in reallocation might be driven by prices rather than quantities. We find that the correlation between $R$ and $R / K$ is 0.9322 in the data.
} 
Figure 3: Impulse Response Functions: TFP shock
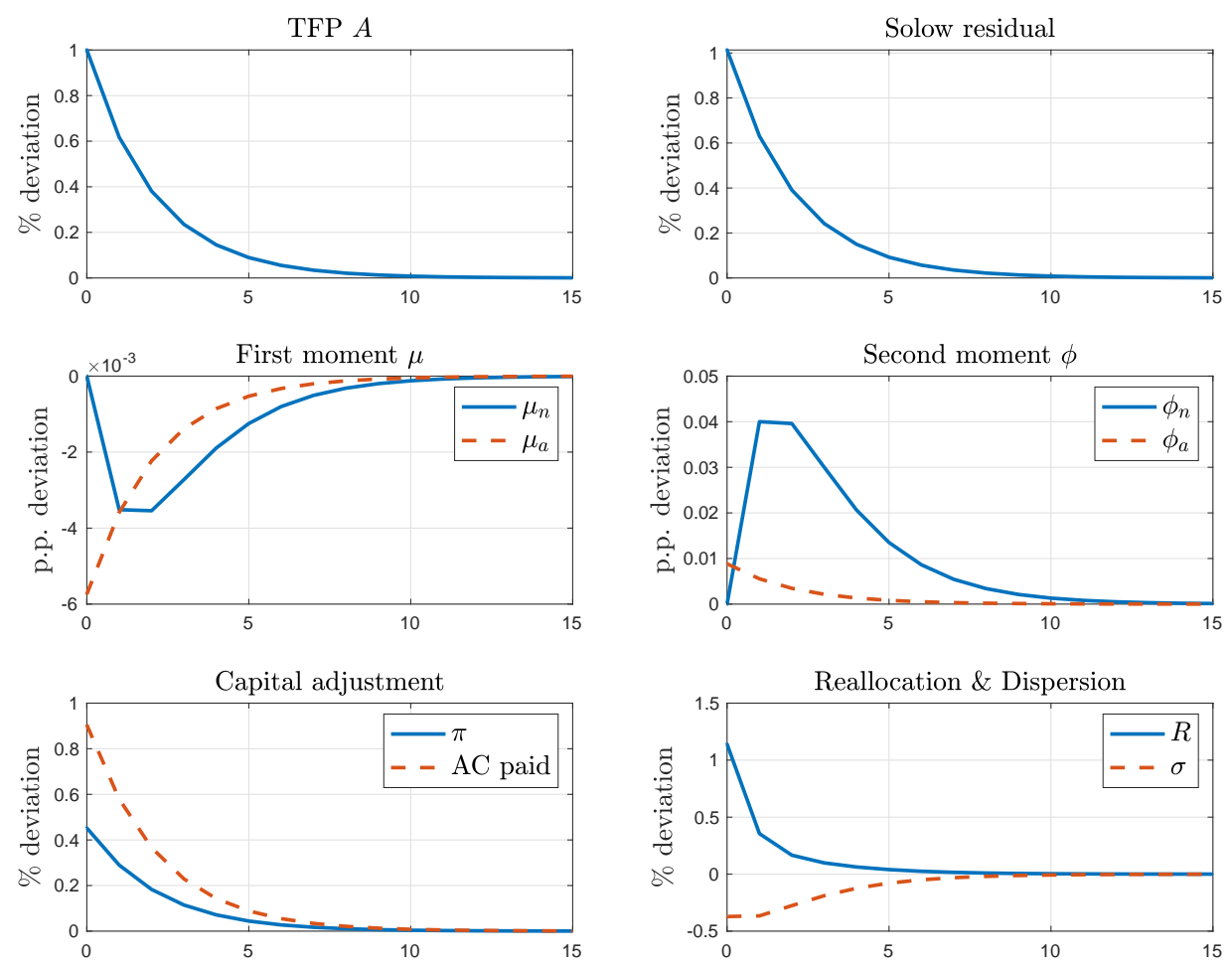

Notes: Responses following a $1 \%$ increase in TFP. The Solow residual is defined in $15 . \pi$ represents the fraction of adjusting firms. AC paid represents the total capital adjustment costs paid. In the last panel, $R$ is the total amount of reallocated capital, while $\sigma$ denotes the dispersion in average products of capital, defined as APK $=A \varepsilon k_{j}^{\alpha-1}$.

\subsection{TFP Shocks}

Consider first the model in which aggregate fluctuations are driven only by shocks to aggregate total factor productivity (TFP). Assume TFP follows an AR(1) in logs:

$$
\log A_{t}=\rho_{A} \log A_{t-1}+\nu_{A, t}, \quad \nu_{A} \sim N\left(0, \sigma_{A}\right)
$$

TFP shocks are well understood as being able to match a number of business cycle moments. In our setup, they also generate an endogenously procyclical fraction of adjusting plants. During expansions the gains to reallocation are increasing, while the costs of adjustment are independent of the current value of productivity. This generates procyclical reallocation and amplifies exogenous aggregate fluctuations.

The row labeled "A Model" in Table 3 shows that this model is able to match the reallocation moments, both qualitatively and quantitatively. The cyclicality of reallocation as well as its magnitude are close to data counterparts.

The mechanism that generates these moments is highlighted by the impulse response functions in Figure 3. Besides a direct effect on production, the positive shock to TFP also increases the benefits of reallocation. Due to the increase in capital reallocation and the persistent nature of the TFP shock, more capital ends 
up in high-productivity plants. The magnitude of this reallocation as well as its correlation with the Solow residual match the data moments. The extensive margin of capital adjustment is procyclical, as in the bottom left panel. Importantly, the model also generates a countercyclical cross-sectional dispersion in plant-level average products of capital. Although untargeted by the model, this feature matches the findings of Eisfeldt and Rampini (2006), Kehrig (2015) and others. The model produces this result because following the TFP shock, a larger fraction of plants adjust capital. Adjusting plants have a lower dispersion in average products. Further, the dispersion declines among adjusting and non-adjusting plants because of the changed target capital allocation, characterized by a higher covariance between capital and productivity $\phi_{a}$.

The panels in the middle row of Figure 3 show the evolution of the two moments of the joint distribution of capital and productivity. The blue solid lines show the evolution of this joint distribution among nonadjusting plants. The red dashed lines show the moments $\mu_{a}$ and $\phi_{a}$ that are implied by the optimal choice of the capital vector $\tilde{k}_{a}$ among adjusting plants. Following an increase in TFP, more capital is assigned to production sites with a high marginal product of capital. This increases $\phi_{a}$ and lowers $\mu_{a}$. Over time, these changes affect the non-adjusting plants because of time-variation in productivity and adjustment status. Together with the increase in the extensive margin of reallocation $\pi$, these dynamics imply an endogenous movement of the Solow residual. From Figure 3, the Solow residual, shown in the top-right panel, is not identical to TFP, precisely because of these endogenous dynamics. However, as was anticipated in Section 3.2 , these indirect productivity effects are small. We discuss the magnitude further below.

\subsection{Variations in the cost of capital adjustment}

The second shock we consider is an exogenous variation in the distribution of the cost of capital reallocation. This can drive procyclical reallocation and thus variations in the Solow residual, while aggregate TFP remains fixed. We assume that $b_{t}$, the upper support of the adjustment cost distribution, follows an AR(1) in logs:

$$
\log b_{t}=\log b+\rho_{b} \log b_{t-1}+\nu_{b, t}, \quad \nu_{b} \sim N\left(0, \sigma_{b}\right) .
$$

Note that the mean of this process is determined by $b$, the value estimated for the steady state of the economy. The parameters $\rho_{b}$, and $\sigma_{b}$ make up the estimated parameter vector.

The moments generated from simulating the model driven by fluctuations in adjustment costs are shown in the "B Model" row of Table 3. The model is able to match both the procyclical reallocation and standard deviation of reallocation moments. In fact, the resulting model moments are virtually the same as in the TFP shock case.

To understand the economic mechanism behind these results, consider a $1 \%$ decrease in $b_{t}$. This implies that reallocation becomes cheaper on the margin. The connection between reallocation and productivity stemming from variations in $b_{t}$ is shown in Figure 4

The decrease in adjustment costs has direct and indirect effects. The direct effect is that on impact, the lower adjustment costs lead to a $3 \%$ increase in the fraction of adjusting plants, $\pi$. Indirectly, changes in $b_{t}$ affect the intensive margin of capital reallocation. Together, the ensuing increase in reallocation of capital increases output and lowers the dispersion of average products of capital. In this way, the economy driven by shocks to $b_{t}$ matches two key empirical regularities: procyclical capital reallocation and countercyclical dispersion in average products of capital.

Three things distinguish the economy's response to variations in $b_{t}$ from that to TFP shocks. First, changes in $b_{t}$ cause fully endogenous movements in the Solow residual. Through the dynamics in $\mu$ and 
Figure 4: Impulse Response Functions: Shock to adjustment costs
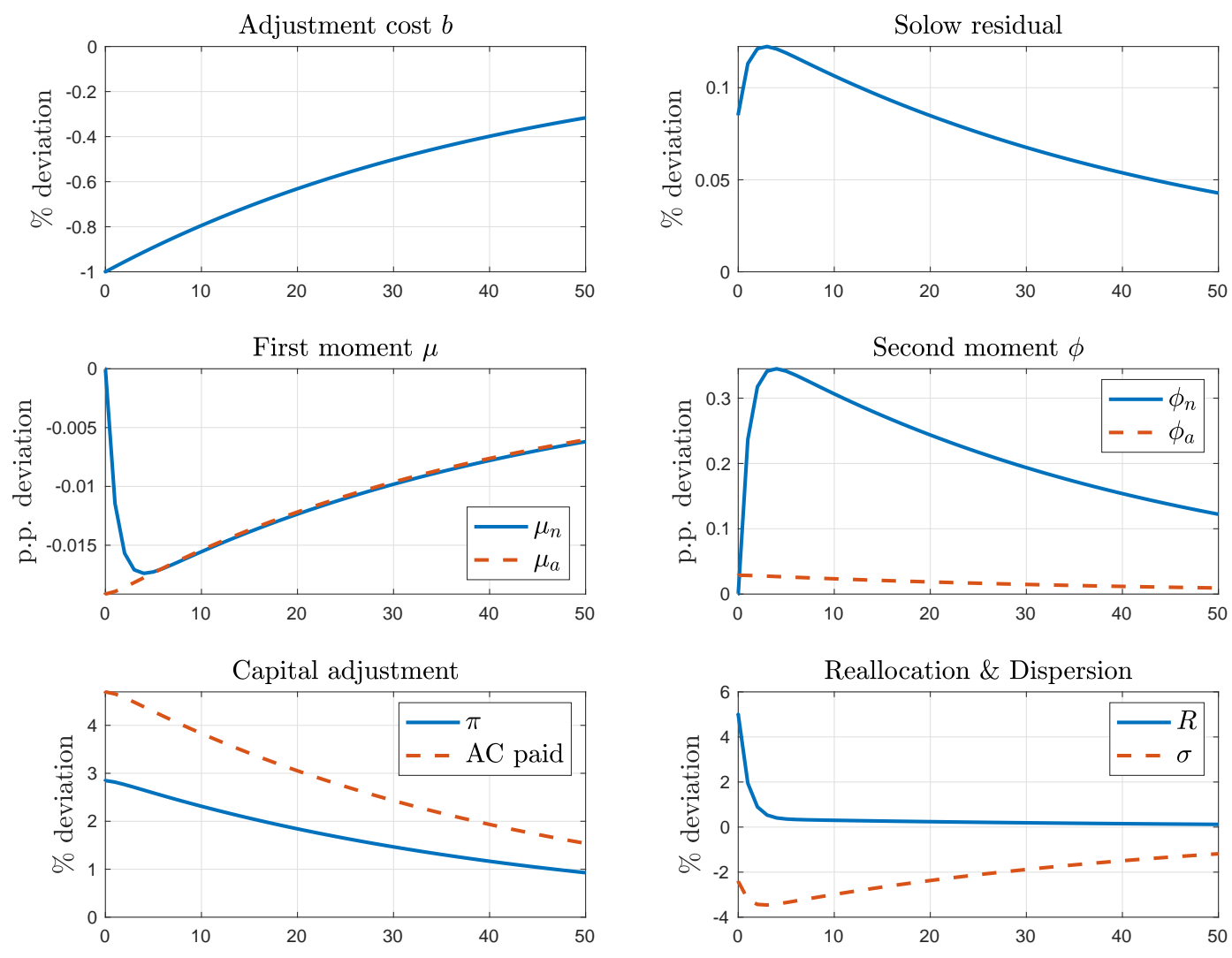

Notes: Responses following a $1 \%$ decrease in the upper bound of the adjustment cost distribution, $b_{t}$. The Solow residual is defined in (15). $\pi$ represents the fraction of adjusting firms. AC paid is total capital adjustment costs paid. $R$ is the total amount of reallocated capital. $\sigma$ denotes the dispersion in average products of capital, APK $=A \varepsilon k_{j}^{\alpha-1}$. Because the estimated persistence of $b_{t}$ is higher than that of $A_{t}$, the 50 periods following the shock are shown.

$\phi$ induced by lower adjustment costs, the evolution of the joint distribution of productivity and capital $\Gamma$ generates endogenous movements in the Solow residual. A reduction in $b_{t}$ leads to an increase in $\pi_{t}$, which from (15) increases productivity directly, and from (11) increases the covariance between productivity and capital among non-adjusting plants. In this way, the shock can generate long-lasting effects on measured productivity.

A second distinguishing feature of the $b_{t}$ shock is the hump-shaped response of productivity. This response is driven by the dynamics of $\phi_{n}$, shown in the middle-right panel. It highlights the importance of this higher-order moment as an integral component connecting reallocation with aggregate productivity. Because changes in $b_{t}$ trigger comparatively large changes in $\pi_{t}$, this implies that over time, adjusting and non-adjusting plants become more similar $\left(c f\right.$. (11)). This effect is hump-shaped although the response of $\pi_{t}$ is not, because i.) there is no effect on $\phi_{n}$ on impact, ii.) it takes time for changes in $\pi_{t}$ to take full effect on the non-adjusting plants, and iii.) mean-reversion implies a slow decrease in $\pi_{t}$ back to its long-run mean, undoing the effect on $\phi_{n}$. While the same dynamics are also present following a shock to aggregate TFP, 
there the direct effect of $A$ on $\tilde{A}$ dominates the productivity dynamics.

Lastly, note that the changes in $b_{t}$ cause comparatively small variations in measured productivity, especially when compared to the large induced changes in the fraction of adjusting plants. This is a key reason for why we find that a quantitatively plausible degree of variability in $b_{t}$ cannot create the empirically observed cyclicality of the Solow residual, as we show in the following, final section of the paper.

\subsection{Aggregate productivity variation}

The previous results showed that both sources of aggregate fluctuations studied were able to match key reallocation moments. However, assessing the contribution of capital reallocation for the variability of the Solow residual, we find that the implications for cyclical variations in the Solow residual coming from the two models are quite different. These differences are highlighted in Figure 5 .

The upshot is that the A model matches the standard deviation of the Solow residual almost exactly while the $\mathrm{B}$ model generates only about $7 \%$ of that variation. The standard deviation of $\tilde{A}$ in the data is $3.9 \%$. In the economy subject to aggregate fluctuations in TFP, calibrated to match the cyclicality of reallocation and the standard deviation of the fraction of reallocated capital, the standard deviation of $\tilde{A}$ is also equal to $3.9 \%$. This moment was not targeted in our calibration of the model. From Figure 5, the vast majority of this variability is the result of variations in TFP, only about $2 \%$ are generated endogenously through capital reallocation. The economy driven by shocks to adjustment costs and calibrated to match the same data targets, on the other hand, creates sizeable endogenous movements in the Solow residual. These endogenous movements in aggregate productivity, however, only amount to $6.7 \%$ of the overall standard deviation in $\tilde{A}$.

Figure 5: Cyclicality of aggregate productivity

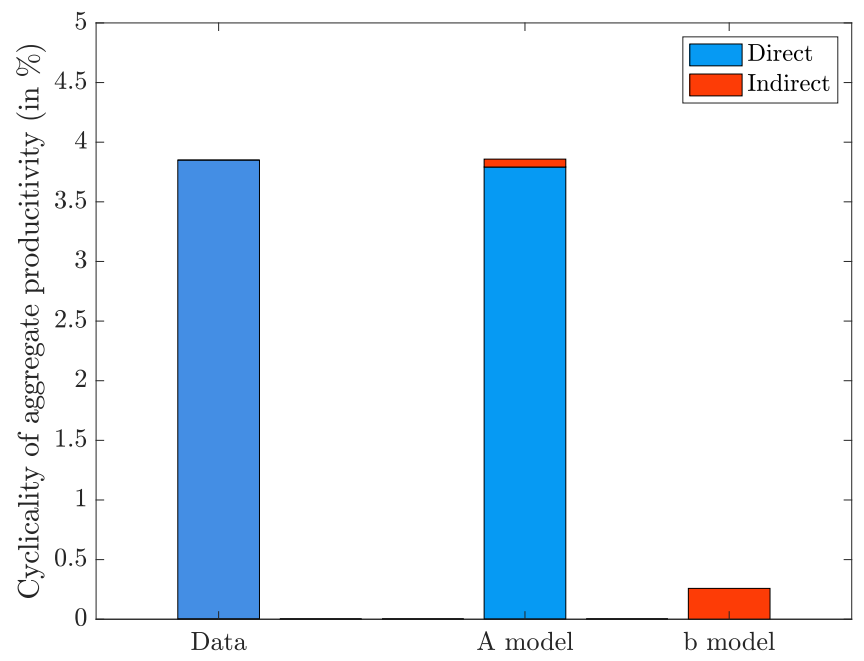

Notes: The left bar shows the cyclicality of measured aggregate productivity in the data. The two bars on the right show the same cyclicality in the model. In the model driven by exogenous variations in TFP, there is a direct effect (from $A$ ) and an indirect effect coming through endogenous changes in the allocation of capital across plants. In the $b$ model, driven by exogenous variations in the cost of reallocation, there is only an indirect effect. 
At the estimated parameters that match the U.S. data, we conclude that variations in the cost of capital reallocation cannot create the empirically observed cyclicality of the Solow residual. Our interpretation of this finding is that the U.S. economy is very efficient in terms of capital reallocation. This reflects both the magnitude of dispersion in productivity across plants as well as the costs of reallocating. Given these estimates, even though reallocation is procyclical, productivity gains from that reallocation are modest.

The result shown in Figure 5 is reminiscent of the steady state result from Section 3.2 , shown in panel b) of Figure 2. A key difference is that our results in Figure 5 were derived from a model with aggregate shocks that were disciplined to generate plausible variations in the amount of capital reallocation and was taking the endogenous model propagation into account.

Importantly, our result does not imply that endogenous changes in capital reallocation can never generate sizeable variations in aggregate productivity. Consider a case where adjustment costs significantly increased, leading to a large reduction in the amount capital reallocation. In this case marginal changes in these adjustment might trigger larger movements in reallocation and productivity. But given the current state of the U.S. economy, reallocation of capital is not a driving force for business cycle dynamics.

One might conjecture that these findings are, in part, a consequence of the specification of capital reallocation costs. Although the specification captures informational frictions in a tractable way, the state dependence of adjustment is certainly limited. If capital adjustment was fully dependent on the firm state $(k, \varepsilon)$, the average effects of reallocation might even be larger. The U.S. economy would appear even more efficient. But then the marginal effects of changes in the extent of reallocation over the cycle would be even smaller. It is in this sense that our specification of adjustment costs does not drive our results and might, in fact, overstate the effects of procyclical reallocation.

\section{Conclusion}

The goal of this paper was to understand the implications of procyclical capital reallocation for aggregate productivity. The framework was the optimal allocation of a planner facing costs of capital reallocation. Aggregate fluctuations were driven either by TFP shocks or variations in the costs of reallocation.

We have two main conclusions. Our first result is that both a model economy with exogenous productivity shocks and an economy with exogenous variations in the costs of reallocation are able to match key moments regarding the cyclicality of reallocation. Both models create realistic amounts of procyclical capital reallocation, while generating countercyclical productivity dispersion across plants.

However, once the implications for aggregate productivity are taken into account, the two models differ substantially. Our second result is that the model with variations in the cost of reallocation generates only about $7 \%$ of the empirically observed variation in the Solow residual.

Although the total amount of capital reallocation is an important determinant of long-run productivity, large average levels of reallocation imply small marginal productivity gains. The overall efficiency of capital allocation in the U.S. limits the gains from reallocation over the cycle. 


\section{References}

Bachmann, R. And C. Bayer (2014): "Investment Dispersion and the Business Cycle," American Economic Review, 104, 1392-1416.

Bartelsman, E., J. Haltiwanger, and S. Scarpetta (2013): "Cross-Country Differences in Productivity: The Role of Allocation and Selection," American Economic Review, 103, 305-334.

Bloom, N. (2009): "The Impact of Uncertainty Shocks," Econometrica, 77, 623-685.

Cooper, R. And J. EJarque (2003): "Financial frictions and investment: requiem in Q," Review of Economic Dynamics, 6, 710-728.

Cooper, R. W. and J. C. Haltiwanger (2006): "On the Nature of Capital Adjustment Costs," The Review of Economic Studies, 73, 611-633.

Cooper, R. W. And I. Schott (2020): "Capital Reallocation and Aggregate Productivity," National Bureau of Economic Research Working Paper Series, No. 19715.

Eisfeldt, A. L. AND A. A. RAmpini (2006): "Capital reallocation and liquidity," Journal of Monetary Economics, 53, 369-399.

Foster, L., J. Haltiwanger, And C. Syverson (2008): "Reallocation, Firm Turnover, and Efficiency: Selection on Productivity or Profitability?" American Economic Review, 98, 394-425.

Guner, N., G. Ventura, and Y. Xu (2008): "Macroeconomic implications of size-dependent policies," Review of Economic Dynamics, 11, 721-744.

Hsieh, C.-T. And P. J. Klenow (2009): "Misallocation and Manufacturing TFP in China and India," The Quarterly Journal of Economics, 124, 1403-1448.

İmrohoroĞLu, A. And Ş. Tüzel (2014): "Firm-Level Productivity, Risk, and Return," Management Science, 60, 2073-2090.

Kaymak, B. And I. Schotт (2019): "Loss-offset provisions in the corporate tax code and misallocation of capital," Journal of Monetary Economics, 105, 1 - 20.

Kenrig, M. (2015): "The Cyclical Nature of the Productivity Distribution," Report, SSRN Working paper.

Krusell, P. And J. A. A. Smith (1998): "Income and Wealth Heterogeneity in the Macroeconomy," Journal of Political Economy, 106, 867-896.

LANTERI, A. (2018): "The Market for Used Capital: Endogenous Irreversibility and Reallocation over the Business Cycle," American Economic Review, 108, 2383-2419.

Lucas, R. E. (1978): "On the Size Distribution of Business Firms," The Bell Journal of Economics, 9, $508-523$.

Maksimovic, V. And G. Phillips (2001): "The Market for Corporate Assets: Who Engages in Mergers and Asset Sales and Are There Efficiency Gains?" The Journal of Finance, 56, 2019-2065. 
Olley, G. S. And A. Pakes (1996): "The Dynamics of Productivity in the Telecommunications Equipment Industry," Econometrica, 64, 1263-1297.

Osotimenin, S. (2019): "Aggregate productivity and the allocation of resources over the business cycle," Review of Economic Dynamics, 32, 180-205.

Ramey, V. A. And M. D. Shapiro (2001): "Displaced Capital: A Study of Aerospace Plant Closings," Journal of Political Economy, 109, 958-992.

Restuccia, D. And R. Rogerson (2008): "Policy distortions and aggregate productivity with heterogeneous establishments," Review of Economic Dynamics, 11, 707-720.

Thomas, J. K. (2002): "Is Lumpy Investment Relevant for the Business Cycle?" Journal of Political Economy, 110, 508-534. 


\section{A Data}

All data targets used in this paper were computed from Compustat. We use the annual Compustat database between 1971 (the first year our measure of capital reallocation is available) and 2018. We delete non-U.S. firms and firms that only appear during a single year. Further, we drop observations with less than $\$ 100 ’ 000$ in sales, total assets, total capital, and those with missing total assets or depreciation. We remove firms in the financial industry and utilities (SIC codes 4900-4999 and 6000-6999). Firm-level capital is computed using a perpetual inventory method.

For the estimation of revenue-based total factor productivity (TFPR), we follow the methodology of Olley and Pakes (1996) as implemented by İmrohoroğlu and Tüzel (2014). The parameter $\alpha$ governing the curvature of the revenue function in the model is computed as $\alpha=\frac{\hat{\alpha}}{1-\hat{\beta}}$, where $\hat{\alpha}$ and $\hat{\beta}$ denote the estimated elasticities of capital and labor. These elasticities were estimated controlling for year and 3-digit industry fixed effects. We find $\hat{\alpha}=.196$ and $\hat{\beta}=.756$, implying $\alpha=0.80$. This estimate of $\alpha$ is higher than some other estimates. In a study of firm level investment, Cooper and Ejarque (2003) estimated the curvature of the firm revenue function at 0.69. At the plant level, Cooper and Haltiwanger (2006) estimate the curvature at 0.592 .

To compute data moments that pertain to capital reallocation we follow Eisfeldt and Rampini (2006). Capital reallocation $R$ is the sum of sales of property, plant and equipment, and acquisitions. The average fraction of capital being reallocated, $R / K$, is the average of $R$ divided by total property, plant, and equipment. The average product of capital (APK) is defined as $Y / K$, sales divided by capital. We compute its dispersion as the the time-series median of the annual value-added weighted standard deviations. Investment is the sum of capital expenditures and acquisitions.

\section{B Derivations}

Frictionless economy Without adjustment costs and with a fixed stock of capital, $K$, the planner's problem is static:

$$
\max _{\tilde{k}_{a}(\varepsilon)} u(c)
$$

subject to

$$
\begin{aligned}
K & =\int_{\varepsilon} \tilde{k}_{a}(\varepsilon) f(\varepsilon) d \varepsilon \\
y & =A \int_{\varepsilon} \varepsilon \tilde{k}_{a}(\varepsilon)^{\alpha} f(\varepsilon) d(\varepsilon), \\
c & =y
\end{aligned}
$$

The optimal allocation of capital across production sites in the frictionless problem follows from the first order condition of B.1, which implies $\alpha A \varepsilon \tilde{k}_{a}(\varepsilon)^{\alpha-1}=\eta$ for all $\varepsilon$, where $\eta$ is the multiplier on B.2. This implies $\tilde{k}_{a}(\varepsilon)=\frac{\eta}{\alpha A \varepsilon}{ }^{\frac{1}{\alpha-1}}$. Using the constraint $(\mathrm{B} .2), \eta=A \alpha K^{\alpha-1}\left(\int_{\varepsilon} \varepsilon^{\frac{1}{1-\alpha}} f(\varepsilon) d \varepsilon\right)^{1-\alpha}$. Putting these two conditions together yields the expression for optimal capital in 77 .

Stationary distribution The laws of motion for the elements of the distribution $\Gamma$ in (10) and (11) imply the stationary values in 12 and 13 . The law of motion 111 makes uses of the fact that $\phi^{\prime}=\operatorname{Cov}\left(\varepsilon^{\prime}, \tilde{k}_{j}^{\alpha}\right)=$ $\operatorname{Cov}\left(\rho \varepsilon, \tilde{k}_{j}^{\alpha}\right)=\rho \phi$ because the covariance between effective capital and productivity among the plants that 
receive a new random realization of $\varepsilon^{\prime}$ is zero. Using the stationary values $(12)$ and $[13)$ in the Solow residual formulated in 15 we obtain the expression for consumption (14) in the main text. The stationary Solow residual is given by

$$
S R=A\left(\mu_{a}+\phi_{a} \cdot \frac{\pi}{1-\rho_{\varepsilon}(1-\pi)}\right)
$$

Reallocation and aggregate productivity In Section 3.2 we calculate the marginal changes in the steady-state Solow residual from changes in $\pi$. For panel (a) of Figure 2 we proceed as follows. For a given, exogenous steady state level of $\pi$ (the x-axis) we solve the optimal capital allocation problem, holding all parameters constant. The result is a changed Solow residual, from (B.5). We then compute the derivative of the Solow residual with respect to $\pi$, which is plotted as the blue line. Note that in $(\mathrm{B} .5), \phi_{a}$ and $\mu_{a}$ are also functions of $\pi$, which is not made explicit in the formula.

To calculate the effect of marginal changes in $A$ or $b$, plotted in panel (b) of Figure 2 , we proceed as follows. From (14) we replace the Solow residual with the expression in (15) and use the function form assumption about the adjustment cost realizations being drawn from a uniform distribution with upper bound $b$. This pins down $\tilde{\pi}(A, b)$, an optimal choice of $\pi$ as a function of $A$ and $b{ }^{18}$ We use this expression in 15 to determine the new Solow residual, $\tilde{S R}$. In panel (b) of Figure 2 we plot the marginal effect of $\tilde{S R}$ with respect to $A$ and $b$.

\section{Sensitivity Analysis}

The SMM estimation of the baseline parameters resulted in a error of $0.006 \%$ average percentage distance between the model moments and data moments. Changing $\alpha$ to 0.7 (from $\alpha=0.81$ in the main text) an almost equally good fit $(0.007 \%)$ was achieved with resulting parameter estimates $b=.2031, \rho_{\varepsilon}=0.80$, and $\sigma_{\varepsilon}=0.3127$. The benchmark values are reported in Table 1 .

Table C.4 shows the sensitivity of the model moments with respect to the parameter vector. The table shows numerical partial derivatives of the model moments with respect to the parameter listed in the first column.

Table C.4: Sensitivity

\begin{tabular}{lrrr}
\hline Parameter / Moment & $\mathrm{R}>0$ & $R / K$ & $\sigma_{\mathrm{TFPR}}$ \\
\hline$\alpha$ & 2.002 & 0.0979 & -0.2789 \\
$b$ & -1.001 & 0.0792 & 0.0687 \\
$\rho_{\varepsilon}$ & -1.001 & -0.3014 & -0.0725 \\
$\sigma_{\varepsilon}$ & 2.002 & 0.0023 & 0.7177 \\
\hline
\end{tabular}

Note.- The first column shows the parameter that is changed. All other parameters are held fixed at their estimated values. In columns (2)-(4) the numerical derivative of the respective moment with respect to the parameter change is shown.

\footnotetext{
${ }^{18}$ For the plots in panel b) we evaluate the derivatives in the steady state, where the effect of changes in $\pi$ on $\phi_{a}$ and $\mu_{a}$ are zero.
} 